\title{
Prospective study of quality of life before and after coronary artery bypass grafting
}

\author{
N Caine, S C W Harrison, L D Sharples, J Wallwork
}

\begin{abstract}
Objectives-Measurement of changes in patients' perceptions of how differing states of health affect their lives and determination of the ability of preoperative variables to predict outcome after coronary artery bypass grafting.

Design-Prospective study with completion of questionnaires before coronary artery bypass grafting and at three months, one year, and five years afterwards.

Setting-Regional cardiothoracic centre.

Patients - 100 Male patients all aged below 60 at the time of operation, who were patients of two cardiothoracic surgeons.

Main outcome measures-Patients' assessment of their health state in terms of functional capacity and aspects of distress, according to the Nottingham health profile and outcome of operation in terms of changes in symptoms, working life, and daily activities determined by self completed study questionnaires before operation and at three and six months afterwards.
\end{abstract}

Results-Intermediate one year results are reported. The differences between the Nottingham health profile scores before operation and at three months afterwards were significantly different $(\mathbf{p}<\mathbf{0 . 0 1})$, indicating an appreciable improvement in general health state, and at one year compared favourably with those from a normal male population. Analysis of responses to the study questionnaire showed that 65 of 89 patients $(73 \%)$ were working at one year after operation with a further seven $(8 \%)$ maintaining that they were fit to work but unable to find employment. The proportion of patients complaining of chest pain fell from $90 \%(88 / 98)$ before grafting to $19 \%(17 / 89)$ at one year after coronary artery bypass grafting, when $91 \%(81 / 89)$ patients maintained that their condition was either completely better or definitely improved. The significant positive factors affecting return to work and home activities were working before operation, short wait for operation, absence of breathlessness, and low physical mobility score in the Nottingham health profile (all $\mathrm{p}<0.001$ ).

Conclusions-Improvements were evident in general health state, symptoms, and activity at three months and one year after coronary artery bypass graft surgery. Interventions likely to influence outcomes included reduction in waiting times for operation; rehabilitation initiatives; and more attention to the quality of information given to patients, their relatives, and the community.

\section{Introduction}

The measurement of outcome of treatment for the patient is the keystone of modern scientific medicine, and its importance is being recognised throughout clinical practice, particularly when innovative, costly, कै or invasive treatments are evaluated or reviewed. Survival rates, test results, return to work figures, and clinical judgment of outcome have been the prevalent methods, mainly because they are more easily measured. Recently, however, the emphasis has been more towards assessing outcome in terms of patients' perceptions of changes in their state of health over time. Both approaches are important and should complement each other.

At this hospital a Department of Health and Social Security study of the costs and benefits of heart transplantation during 1982-4, which included a comparison group of patients with coronary artery bypass grafts $^{1}$ formed the background to the development of this long term prospective study. A questionnaire to accompany the Nottingham health profile was developed from two sources: an extensive literature search for reports on outcome studies of coronary artery bypass graft surgery and the experience gained by the research team of the Department of Health and Social Security in their interviews with heart transplant patients. The ability to compare results in patients undergoing heart transplantation and coronary artery bypass operations was an important consideration, which is reported elsewhere. ${ }^{2}$

\section{Patients and methods}

One hundred male patients aged below 60 at the time of operation were included in the study: all were patients of two cardiothoracic surgeons and were not otherwise selected. Their mean age was 51 (SD 6), range 37-59; 77 had three vessel disease and 84 needed three bypass grafts or more. The 100 patients were not consecutive cases, owing to problems of continuity arising from changes in junior surgical staffing during this period. Emergency admissions were excluded because of the need to obtain data before surgery.

On admission for coronary artery bypass grafting the patients' consent to the study was obtained, and the first questionnaires were completed. At three months and 12 months after surgery further questionnaires were sent to the patients by post, after we had first contacted their general practitioners to ensure that to their knowledge the patients were still alive. In the event of a delay in the return of the questionnaires the patient was contacted by telephone.

The purpose designed questionnaire was six pages long and largely comprised questions with yes/no answers, although space was allowed for additional details and comments. Questions were divided into five sections: working life, financial aspects, assessment of symptoms, and daily activities, plus a section on the overall quality of life, expectations before operation, and any problems or benefits experienced afterwards.

The Nottingham health profile was developed by a team in the department of community health at 
Nottingham University in the late 1970 s. ${ }^{3}$ Used widely in studies in the United Kingdom, it has proved sensitive to a wide range of health states and is acceptable to patients when used regularly over a prolonged period. ${ }^{14}$ The profile is divided into two parts. The first consists of 38 statements that convey limitations of activity or aspects of distress in six dimensions: physical mobility, pain, sleep, energy, social isolation, and emotional reactions. Patients are required to indicate by a yes/no answer which of the problems they are experiencing at the time of completing the questionnaire. A score ranging from 0 to 100 may be calculated for each dimension of this part of the profile; the higher the score, the greater the limitations in activity or the distressing social and emotional problems. The second part lists the seven aspects of life which the Nottingham team found were most affected by a person's state of health: occupation, ability to perform jobs around the house, social life, home relationships, sex life, hobbies, and holidays; a yes/no answer indicates which areas are affected by the respondent's present state of health.

\section{STATISTICAL ANALYSIS}

Statistical analysis of the data obtained from the profile was performed using non-parametric tests. For comparisons before and after coronary artery bypass grafting Wilcoxon's matched pairs signed ranks test was used for scores in the first part of the profile and McNemar's test for the responses in the second. Scores obtained after coronary artery bypass grafting were compared against expected scores for a normal population with the same age and sex characteristics by Wilcoxon matched pairs signed ranks test. Associations between outcome and variables measured before artery bypass grafting were assessed with the $\chi^{2}$ test for contingency tables with Yates's correction. Differences between outcome groups in terms of scores according to the Nottingham health profile were assessed with Wilcoxon's rank sum test.

To investigate the ability of variables measured preoperatively to predict outcome, in terms of return to work and home and leisure activities, and to study them in a multivariate setting discriminant analysis was used. The Nottingham health profile scores were categorised as above and below twice the expected score for a normal population having the same age and sex structure as that of our sample. With discriminant analysis each indicant is given a "value" for or against the outcome of interest - for example, return to work in the first year-termed a "weight of evidence." A positive value indicates evidence for the outcome of interest, and a negative value evidence against. If the sum of all the values passes a preset threshold then the patient is classified as having more than a $50 \%$ chance

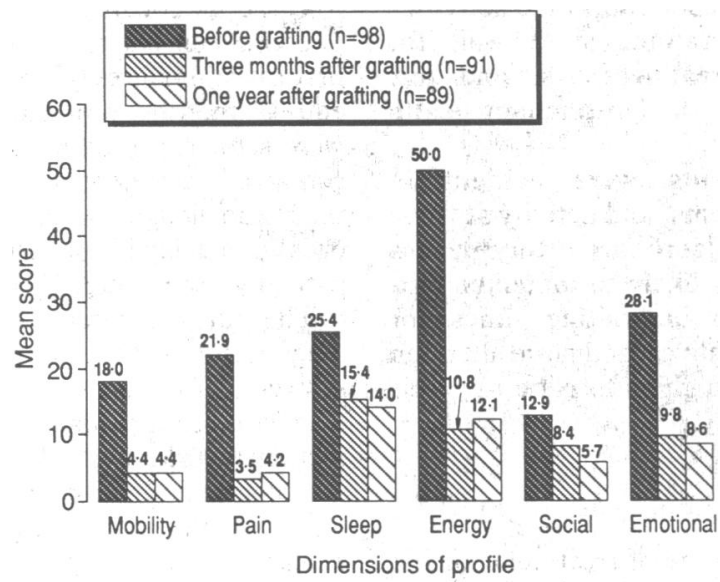

FIG 1-Mean scores for Nottingham health profile (part I) in patients before and after coronary artery bypass grafting
TABLE I-Mean scores for Nottingham health profile (part I) in patients at one year after coronary artery bypass grafting compared with those in a normal male population *

\begin{tabular}{lccc}
\hline & & \multicolumn{2}{c}{ Normal male population } \\
\cline { 3 - 4 } Dimensions & $\begin{array}{c}\text { Patients } \\
(\mathrm{n}=89)\end{array}$ & Aged 50-54 & Aged 55-59 \\
\hline Physical mobility & $4 \cdot 4$ & $4 \cdot 1$ & $3 \cdot 7$ \\
Pain & $4 \cdot 2$ & $7 \cdot 1$ & $2 \cdot 9$ \\
Sleep & $14 \cdot 0$ & $13 \cdot 4$ & $11 \cdot 7$ \\
Energy & $12 \cdot 1$ & 11.6 & $13 \cdot 3$ \\
Social isolation & $5 \cdot 7$ & 5.5 & $3 \cdot 4$ \\
Emotional reactions & 8.6 & 10.6 & $7 \cdot 7$ \\
\hline
\end{tabular}

^2173 Randomly selected men aged 50-59 from general practice.

of having the outcome of interest, and if the threshold is not reached there is less than a $50 \%$ chance of the patient having that outcome.

\section{Results}

Preoperatively four of the 100 patients failed to complete the questionnaires, two the Nottingham health profile, and two the purpose designed questionnaire. Both questionnaires were completed by 91 respondents at three months and 89 respondents at one year after coronary artery bypass grafting. All but two patients were known to be alive one year after coronary artery bypass grafting; these could not be traced and were thought to have moved away from the area. The other non-respondents were contacted by telephone but still failed to return the questionnaires.

\section{NOTTINGHAM HEALTH PROFILE}

The mean scores from the first part of the profile gave a general impression of the state of health of patients before and after coronary artery bypass grafting (fig 1). The lower mean scores after grafting in all six dimensions indicated an overall improvement in quality of life. This was further supported by the statistical analysis of profiles completed by the same individual patients before operation and at three months afterwards. By Wilcoxon's matched pairs signed ranks test significant differences were apparent in all six dimensions of the first part of the profile $(p<0 \cdot 01)$.

Table I shows the mean scores from the profiles completed at one year after operation compared with those from a normal male population (2173 randomly selected men from a general practice) ${ }^{6}$ in the $50-59$ year age group. Apart from a slightly higher score in the dimension of sleep, the scores seemed similar and proved to be so when tested statistically.

Figure 2 shows the proportion of patients indicating that their current state of health was causing problems in seven aspects of daily living, before and after operation. There was a general reduction in affirmative responses at three months after operation, which was highly significant for all seven aspects of life by McNemar's test for paired comparisons $(p<0 \cdot 001)$.

\section{QUESTIONNAIRE}

Working life

Half of the patients were still at work in the immediate preoperative period. All patients were asked about their usual form of employment and about any changes in their working lives since the onset of illness. The ratio of manual to non-manual occupations was $55 \%$ (54 patients) to $43 \%$ (42); two patients failed to indicate their type of employment. Some men's jobs had changed because of their illness, with 37 doing lighter work and 17 working shorter hours, but only 11 had actually changed employment. Three months after operation 39 of the 91 patients replying (43\%) were back at work, and by one year the figure was 65 of 89 $(73 \%)$. Of the 49 patients who were working before bypass grafting, $39(80 \%)$ were known to have returned 


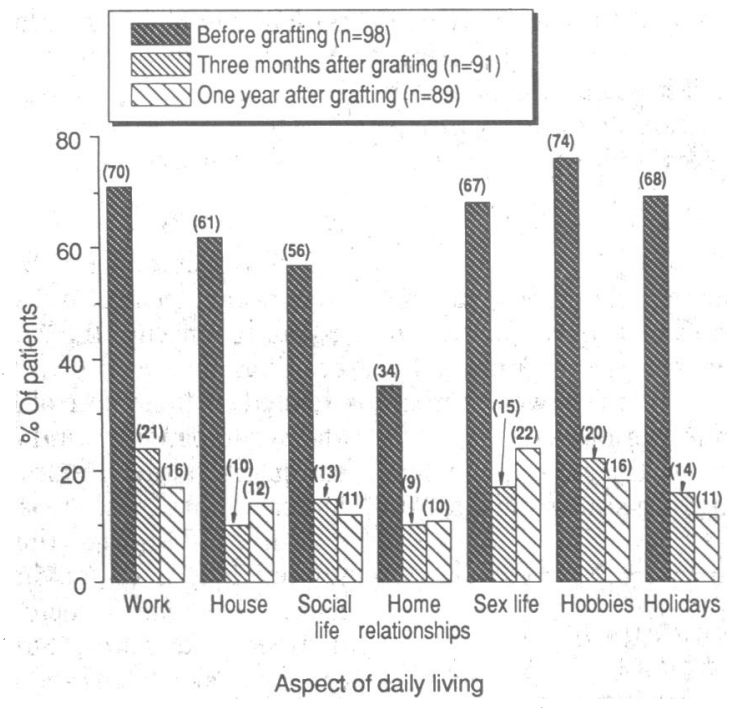

FIG 2-Percentage (number) of patients experiencing problems in seven aspects of daily life before and after coronary artery bypass grafting according to the Nottingham health profile (part II)

to work by one year after operation. Of the 65 patients working at one year, $39(60 \%)$ were in manual occupations and $26(40 \%)$ in non-manual occupations; $14(22 \%)$ were doing a different job from that before grafting. Further differences in type of job after operation included lighter work (12 (18\%) patients) and fewer hours $(10(15 \%))$. Fewer patients were enjoying work "very much" (33 (51\%) v $67(68 \%)$ preoperatively), but more were finding it enjoyable "on the whole" (26 $(40 \%) v 27$ (28\%) preoperatively). Of the 24 patients who were not working at one year, seven $(29 \%)$ were planning to return to work, and a further seven stated that they were fit to work but could not find a job. Fifteen $(63 \%)$ believed that their history of heart disease had made getting a job more difficult.

We examined several variables that might affect patients' ability or opportunity to work or to return to work.

Univariate analysis of return to work-Breathlessness was the symptom most strongly associated with patients' ability to work. Of the 49 patients who were not working preoperatively, $36(74 \%)$ had breathlessness compared with $26(53 \%)$ of the 49 who were working $(p=0.0593)$. At three months after operation breathlessness and chest tightness were significantly more prevalent among the non-workers $(23 / 52(44 \%) v$ $4 / 39(10 \%), \mathrm{p}<0.01 ; 12 / 52(23 \%)$ v $2 / 39(5 \%)$, $\mathrm{p}<0.01)$. At one year after operation a significantly higher proportion of non-workers were experiencing all symptoms, with breathlessness showing the most

TABLE II-Symptoms among patients working or not working before and after coronary artery bypass grafting. Figures are numbers (percentage) of patients

\begin{tabular}{|c|c|c|c|c|c|c|}
\hline & \multicolumn{2}{|c|}{ Before grafting } & \multicolumn{2}{|c|}{ Three months after grafting } & \multicolumn{2}{|c|}{ One year after grafting } \\
\hline & $\begin{array}{l}\text { Working } \\
(n=49)\end{array}$ & $\begin{array}{c}\text { Not working } \\
(n=49)\end{array}$ & $\begin{array}{l}\text { Working } \\
(\mathrm{n}=39)\end{array}$ & $\begin{array}{c}\text { Not working } \\
(\mathrm{n}=52)\end{array}$ & $\begin{array}{l}\text { Working } \\
(\mathrm{n}=65)\end{array}$ & $\begin{array}{l}\text { Not working } \\
\quad(n=24)\end{array}$ \\
\hline Breatl & $26(53)$ & $36(73)$ & $4(10)$ & $23(44)$ & $12(18)$ & $17(71)$ \\
\hline Chest tightness & $30(61)$ & $36(73)$ & $2(5)$ & $12(23)$ & $9(14)$ & $8(33)$ \\
\hline Chest pain & $43(88)$ & $45(92)$ & $6(15)$ & $13(25)$ & $8(12)$ & $9(38)$ \\
\hline Other & $21(43)$ & $21(43)$ & $2(5)$ & $7(13)$ & $3(5)$ & $9(38)$ \\
\hline
\end{tabular}

significant difference between workers and non-workers $(12 / 65(18 \%) v 17 / 24(71 \%)$ respectively, $\mathrm{p}<0.001)$ (table II). Asked whether they had another condition that affected their physical activity or work, 12 patients answered yes preoperatively, 16 at three months, and 18 at one year. As might be expected, a high proportion were non-workers: nine (75\%) preoperatively, 15 $(94 \%)$ at three months after operation, and $10(56 \%)$ at one year. Two of the most significant positive factors affecting return to work were working preoperatively $(p<0.0001)$ and the fact that a job had been held open $(\mathrm{p}<0.01)$. Nottingham health profile scores before grafting were significantly associated with return to work in three dimensions: physical mobility $(\mathrm{p}<0.01)$, energy $(p<0.01)$, and emotional reactions $(p<0.05)$. The lower the scores, indicating fewer restrictions, the more likely patients were to return to work. The age of the patient, the type of work done - that is, manual or non-manual - the length of time with an employer, or the length of time in a particular job were not significant factors.

Predictors of return to work-The significant factors in the discriminant analysis that had a positive effect on return to work by one year after operation were working preoperatively, the length of time waiting for grafting, the absence of breathlessness before operation, and a score for physical mobility lower than twice that of the normal population $(p<0.001)$. The ideal patient had worked in the six months before operation, waited less than a month, was not breathless, and did not have more than twice the normal score for physical mobility; such a patient had a "value" of zero. For each detrimental characteristic a "weight of evidence" for non-return to work was added to the value. For example, a patient with breathlessness increased the value by $0 \cdot 84$. If the total sum of evidence exceeded 6.65 for a particular patient that patient had a greater than $50 \%$ chance of not returning to work. With this method of predicting work state the discriminant programme had a sensitivity of $77 \cdot 9 \%$ and a specificity of $75 \cdot 0 \%$ (table III).

\section{Financial aspects}

Preoperatively 49 patients said that they were financially less well off as a result of their illness, although 51 were still receiving a salary. Figure 3 shows the level of financial dependence of the patient receiving state aid and a partner's income. There was a definite trend towards greater independence after operation in terms of benefits received and reliance on a partner's income, though the trend with regard to pensions was less clear. At one year after operation 22 patients declared that there had been some improvement in their overall financial position whereas 31 said that they were still worse off financially compared with before their illness.

\section{Assessment of symptoms}

Preoperatively $88(90 \%)$ of the group complained of chest pain and $62(63 \%)$ experienced breathlessness. After grafting the proportion with pain had fallen to $21 \%(19)$ at three months and $19 \%(17)$ at one year and with breathlessness to $30 \%(27)$ at three months and $33 \%$ (29) at one year (fig 4). In patients experiencing symptoms, however, the level of exertion at which

TABLE III - Discriminant coefficients for variables measured before coronary artery bypass grafting that affected subsequent return to work and home activities

\begin{tabular}{|c|c|c|c|c|c|c|c|c|c|c|c|c|c|c|}
\hline \multirow{2}{*}{$\begin{array}{l}\text { Discriminatory } \\
\text { variables }\end{array}$} & \multicolumn{3}{|c|}{$\begin{array}{l}\text { Time last worked } \\
\text { (months) }\end{array}$} & \multicolumn{3}{|c|}{$\begin{array}{l}\text { Waiting time for operation } \\
\text { (months) }\end{array}$} & \multicolumn{3}{|c|}{ Quality of life } & \multicolumn{2}{|c|}{ Breathlessness } & \multicolumn{2}{|c|}{ Physical mobility score } & \multirow{2}{*}{$\begin{array}{l}\text { Discriminan } \\
\text { threshold }\end{array}$} \\
\hline & $0-6$ & $6-12$ & $>12$ & $>1$ & $1-3$ & $>3$ & Poor & Average & Good & Yes & No & Normal & High & \\
\hline Return to work by one year* & 0 & $2 \cdot 09$ & $4 \cdot 18$ & 0 & 0.64 & $1 \cdot 28$ & 0 & 0 & 0 & 0.84 & 0 & 0 & 1.54 & $6 \cdot 65$ \\
\hline Return to unrestricted home life by one year $t$ & 0 & 0.90 & 1.80 & 0 & 1.09 & $2 \cdot 18$ & $2 \cdot 5$ & $1 \cdot 25$ & 0 & 1.62 & 0 & 0 & 0 & $6 \cdot 13$ \\
\hline
\end{tabular}

${ }^{\star} \mathrm{p}<0.0001$ For all discriminatory variables.

tp $<0.001$ For all discriminatory variables. 
these symptoms were evident was different before and after grafting. Before grafting 48\% (46/96) of patients who had symptoms did so at rest whereas at one year after grafting climbing stairs, running, or heavy lifting brought on symptoms for $68 \%(25 / 37)$ of patients (fig 5).

\section{Patients' assessment of outcome}

Patients gave an overview of the effect of the operation on their condition on a scale from "worse" to "completely better." By one year after grafting 81 (91\%) of 89 patients said that they were either "completely better" or "definitely improved."

Patients were also asked to rate their overall quality of life before and after grafting on a scale from 0 to 10 ,

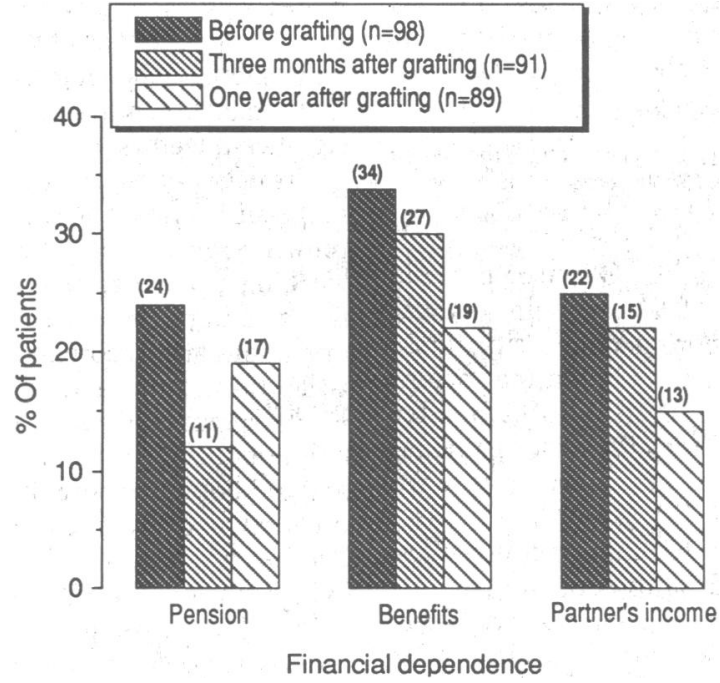

FIG 3-Financial dependence of patients receiving state aid and partner's income before and after coronary artery bypass grafting

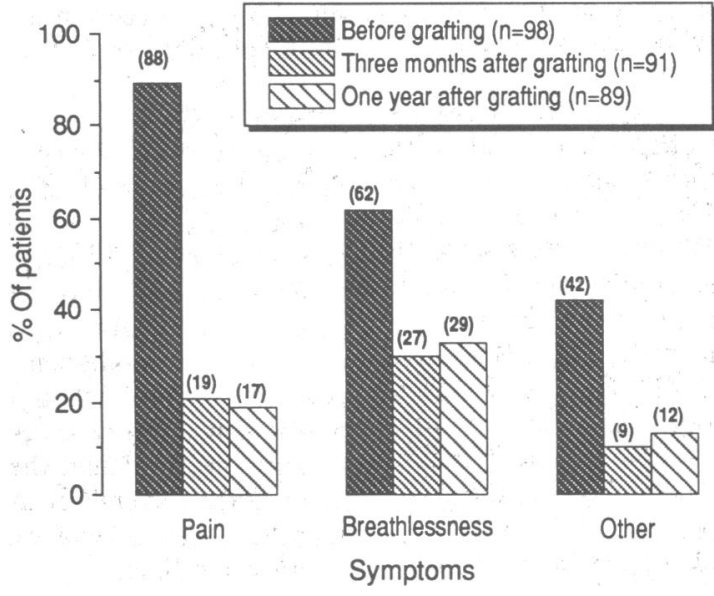

FIG 4-Presence of symptoms before and after coronary artery bypass grafting

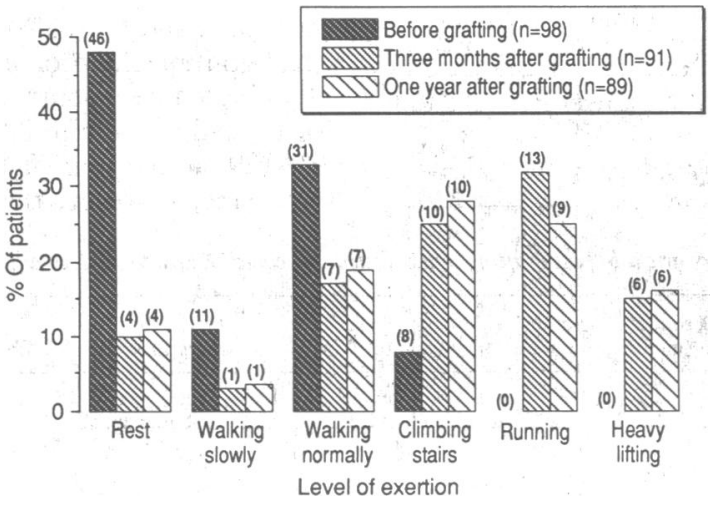

FIG 5-Level of exertion precipitating symptoms before and after coronary artery bypass grafting with higher figures representing a better quality of life. As figure 6 shows, most patients rated their quality of life preoperatively in the middle range, between 4 and 7 , whereas one year after grafting 62 patients gave a rating between 8 and 10 .

\section{Daily activities}

The aspects of daily life included in the questionnaire were home, leisure, and social activities. Patients were asked to specify their usual activities under these headings and to say to what degree each had been affected by their state of health before bypass grafting and at three months and one year afterwards. Figure 7 summarises the results from those patients who indicated that these areas of activity were part of their daily lives. The proportion of patients who experienced no restrictions in looking after the home increased from $17 / 91$ (19\%) before grafting to $70 / 85(82 \%)$ one year afterwards. Similar changes were noted in recreational pursuits and social life with the proportion of patients experiencing normal activity rising from $5 \%$ $(4 / 84)$ to $82 \%(58 / 71)$ and $19 \%(13 / 70)$ to $88 \%(64 / 73)$ respectively.

Univariate analysis of return to unrestricted activityIn home activities low scores according to the Notting ham health profile before grafting were significantly associated with fewer restrictions at one year after operation in three dimensions: physical mobility $(\mathrm{p}<0.01)$, energy, and sleep (both $\mathrm{p}<0.05)$. No association could be found between the scores before grafting and return to leisure activities. For social life, however, unrestricted activity at three months was significantly associated with lower scores before grafting in four dimensions: physical mobility, pain, social isolation $(p<0.05)$, and emotional reactions $(p<0.01)$. At one year after grafting an unrestricted social life was significantly associated with lower scores for physical mobility before grafting $(\mathrm{p}<0.01)$. Work history before grafting was again an important factor. The shorter the non-working time the less restricted patients were at one year after operation in home $(p<0.01)$, leisure $(p<0.01)$, and social $(p<0.001)$ activities. Breathlessness as a symptom before grafting was significantly associated with more restrictions in home activities at one year afterwards $(p<0 \cdot 01)$. A low quality of life rating before grafting indicated a significantly greater chance of being restricted in hobbies at three months $(\mathrm{p}<0.001)$, in home activities at one year $(\mathrm{p}<0.05)$, and in social activities at three months $(\mathrm{p}<0.05)$ and one year $(\mathrm{p}<0.01)$.

Predictors of return to unrestricted activity -Because so few patients experienced restrictions in leisure and social activities before surgery it was not possible to consider a multivariate analysis. In the discriminant analysis of preoperative factors affecting return to unrestricted home life at one year the significant factors were working preoperatively, waiting time, quality of life assessment, and breathlessness (all $p=0.001)$. The ideal patient for return to unrestricted activity worked up until the operation, waited less than one month, had no breathlessness, and rated his or her quality of life as good. Departures from this ideal increased the weight of evidence for restricted home life. If the total exceeded $6 \cdot 13$ for any patient that patient had a greater than $50 \%$ chance of having restrictions in home life postoperatively. With this method of classifying patients into those with restricted and unrestricted activity the sensitivity and specificity were $69 \cdot 2 \%$ and $83 \cdot 3 \%$ respectively (table III).

\section{Problems}

A proportion of patients had experienced problems as well as benefits after graft surgery, but for many these were temporary. Some of the commonest physical problems, mentioned by $25(28 \%)$ of patients at 


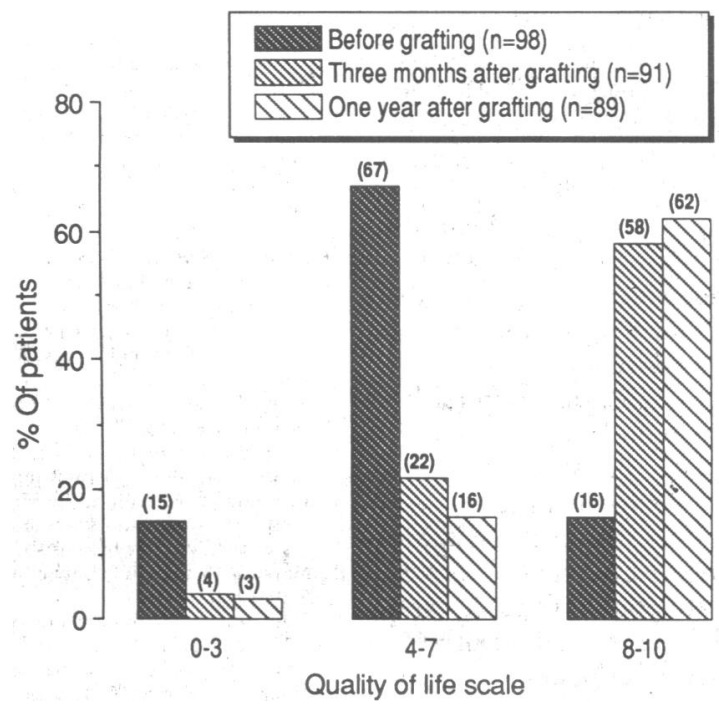

FIG 6-Quality of life scale before and after coronary artery bypass grafting

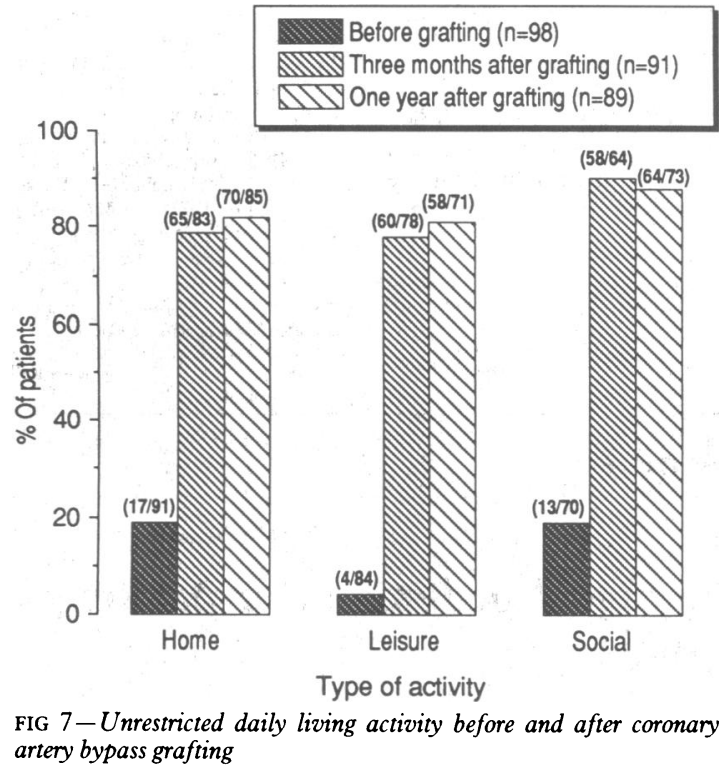

three months and $23(26 \%)$ at one year were muscle stiffness; pain in the chest or leg; gain in weight, sometimes associated with giving up smoking; sexual limitations; tiredness; and the inability to do heavy manual work, particularly lifting. Behavioural problems, experienced by $5(6 \%)$ patients at three months and $6(7 \%)$ at one year included irritability, lack of concentration, and relationship problems with those who treated them like an "invalid." In several cases problems had been experienced with employers and insurance companies: this was true for $3(3 \%)$ patients at three months and $6(7 \%)$ at one year. Interestingly, all except two patients who specified problems also described the benefits they had experienced from their surgery. Apart from the obvious delight expressed by many patients at their return to a normal way of life, patients also alluded to an increased feeling of security about the future and believed that their life expectancy had been extended.

\section{Discussion}

When referred to this hospital for possible coronary artery bypass graft surgery, patients are assessed for their suitability on the criteria of severity and distribution of disease, the extent and severity of symptoms, and the effects of these clinical factors on their quality of life. No structured rehabilitation programme is offered to patients after grafting; they are seen by their surgeon six weeks after the operation and by their cardiologist at three months. Advice is given on reduction of risk factors; taking exercise; following a healthy diet, including reducing intake of cholesterol; and not smoking. Before operation patients are told that they can expect to return to normal activity, including work, at two to three months after their operation; this message is confirmed at the follow up clinics.

Our figure for return to work of $73 \%$ (65 patients) at one year is better than the results from several recent studies in Europe and the United States. ${ }^{7-10}$ In a report from Oxford in $1987,{ }^{11} 46 \%$ of 79 men aged below 65 were working before bypass grafting and $56 \%$ of 71 were working at one year after surgery. In studies over the past 10 years or so the percentage of patients returning to paid employment has continued to vary greatly, and several factors have been associated with rates of return to work. ${ }^{12}$ Whether or not a patient is working and the length of time out of work before grafting are two of the most commonly quoted factors. Age, type of employment, symptoms severe enough to limit activity, and length of time waiting for operation have all been shown to affect postoperative working state.

The study population comprised men aged below 60 at the time of operation, who were engaged in a whole range of types of employment; $77 \mathrm{had}$ three vessel disease and 84 needed three or more grafts. There was therefore no particular selection bias in our study population in terms of social class or severity of disease. Our selection of all male patients aged below 60 was to allow better comparison with heart transplant patients. ${ }^{2}$

Reducing waiting times to a minimum would be one positive move likely to affect outcome in terms of return to work and other activity. ${ }^{13}$ Another recently advocated intervention is a physical rehabilitation programme designed to encourage patients to fulfil their potential after operation. ${ }^{14}$ is Links between psychological factors and return to activity have led to demands for greater attention to patients' psychological attitudes for wellbeing. ${ }^{16} 17$ Such measures require mainly non-surgical staff time and fairly modest facilities and therefore have fewer economic or political implications than the reduction of waiting lists, thus making them perhaps more practical propositions for immediate and effective intervention.

In the 1980s reports on the outcome of coronary artery bypass grafting included return to work as only one of several factors considered important to the success of the procedure. Attention centred increasingly on measures of general activity and on patients' own assessment of their quality of life and satisfaction with outcome.$^{811}$ This study propounds the advantages of a prospective design, following the same group of patients from before grafting to long term follow up, and using at least one measure that allows comparison with a general population.

It might be argued that the fact that patients' knowledge of their participation in a trial of this kind might lead to bias in the results owing to patients exaggerating their assessment of improvement after operation to please their doctors. This is a common problem, for which it is difficult to make adjustments, either in the design of the study or in the analysis of results. Return to work after operation is a fairly objective measure of wellbeing whereas other self assessments of return to activity may be more open to distortion. However, as the improvements in the scores of the Nottingham health profile, were so overwhelming the underlying improvements are probably real.

The results provide evidence of clear benefit to a high proportion of patients undergoing coronary artery bypass grafting in terms of their own assessment of their functional ability and general wellbeing before 
surgery and up to one year afterwards. We are currently investigating these patients again at five years from operation to report on the longer term outcome. Combined with the excellent survival data on patients with bypass grafts in various centres ${ }^{18}{ }^{19}$ our evidence supports the argument that resources allocated to this form of intervention are well spent. For this conclusion to be universal, however, every major centre should evaluate its own work. Continued monitoring of results is important in itself but particularly so when major changes in practice have occurred or are being contemplated. Extending the selection criteria to incorporate older patients and the advent of alternative forms of treatment, such as angioplasty, are just two examples particularly relevant to bypass surgery.

To assess fully the effects of treatment it is vital to take baseline measurements before intervention as well as at intervals afterwards. Preoperative variables and measurements that are found to be associated with the rate and extent of rehabilitation after operation might lead to changes in selection or management-for example, in timing of surgery - which would benefit individual patients and the health service in terms of the best possible use of resources allocated to coronary artery bypass surgery.

We thank Sir Terence English, whose patients are included in our study population, for his support; the consultant cardiologists who referred patients for surgery; and all the patients who completed the questionnaires.

1 Buxton M, Acheson RM, Caine N, Gibson S, O'Brien B. Costs and benefits of the heart transplant programmes at Harefield and Papworth Hospitals: final report. London: HMSO, 1985.
2 Wallwork J, Caine N. A comparison of the quality of life of cardiac transplant patients and coronary artery bypass graft patients before and after surgery. Quality of Life and Cardiovascular Care 1985;1:317-31.

3 McEwen J. The Nottingham Health Profile: a measure of perceived health. In: Teeling-Smith G, ed. Measuring the social benefits of medicine. London: Office of Health Economics, 1985:75-84.

4 Hunt SM, McEwen J, McKenna SP. Measuring health status: a new tool for clinicians and epidemiologists. $\mathcal{F}$ R Coll Gen Pract 1985;35:185-8.

5 Spiegelhalter DJ. Statistical aids in clinical decision making. The Statistician 1982;31:19-36

6 Hunt SM, McEwen J, McKenna SP. Perceived health: age and sex comparisons in the community. I Epidemiol Comm Health 1984;38:156-60.

7 Morton JR, Tolan KM. Activity level and employment status after coronary bypass surgery. Am F Surg 1982;143:417-20.

8 Jenkins CD, Stanton BA, Savageau JA, Denlinger P, Klein MD. Coronary artery bypass surgery: physical, psychological, and economic outcomes six months later. $\mathcal{F} A M A$ 1983;250:782-8.

9 Gehring J, Koenig W, Rana NW, Mathes P. The influence of the type of occupation on return to work after myocardial infarction, coronary angioplasty and coronary bypass surgery. Eur Heart $\mathcal{f}$ 1988;9(suppl L):109-14.

10 Laird-Maeter K, Erdman RAM, Van Domburg R, et al. Probability of a return to work after either coronary balloon dilatation or coronary bypass surgery. Eur Heart I 1989;10:917-22.

11 Mayou R, Bryant B. Quality of life after coronary artery surgery. Q J Med 1987;62:239-48.

12 Walter PJ. Return to work after coronary artery bypass surgery. Eur Heart $\mathcal{X}$ 1988;9 (suppl L):58-66.

13 Oakley CM. Is there life after coronary artery surgery? $Q \mathcal{H}$ Med 1987;62:181-2. 4 Monpere C, Francois G, Roncleau du Noyer C, Phan Van J. Return to work after rehabilitation in coronary bypass patients. Role of the occupational medicine specialist during rehabilitation. Eur Heart $\mathcal{f}$ 1988;9 (suppl L) 48-53.

15 Danchin N, Goepfert PC. Exercise training, cardiac rehabilitation and return to work in patients with coronary artery disease. Eur Heart $\mathcal{f} 1988 ; 9$ (suppl $M$ ): $43-6$.

16 Kornfeld DS, Heller SS, Frank KA, Wilson SN, Malm JR. Psychological and behavioral responses after coronary artery bypass surgery. Circulation 1982;66 (suppl III):24-8.

17 Cay EL, Walker DD. Psychological factors and return to work. Eur Heart $f$ 1988;9 (suppl L):74-81.

18 English TAH, Bailey AR, Dark JF, Williams WG. The UK cadiac surgical register, 1977-82. BMF 1984;289:1205-8.

19 Myers WD, Davis K, Foster ED, Maynard C, Kaiser GC. Surgical survival in the coronary artery surgery study (CASS) registry. Ann Thorac Surg 1985; 40:245-60.

(Accepted 27 November 1990 )
Elective tracheostomy should be considered in patients ventilated for chickenpox pneumonia

General Intensive Care

Unit, St George's Hospital, London SW17 0QT

O F Boyd, MRCP, research registrar

R M Grounds, FCANAES, consultant anaesthetist

Correspondence to: Dr Boyd.

BMf 1991;302:516-7

\title{
Lesson of the Week
}

\section{Life threatening laryngeal oedema after prolonged intubation for chickenpox pneumonia}

\author{
O F Boyd, R M Grounds
}

Guidelines for timing tracheostomy in patients on ventilators remain vague. ${ }^{1}$ Studies of this problem, ${ }^{23}$ and specifically the complications of endotracheal intubation, ${ }^{+}$do not take into account the type of disease in either the results or recommendations. We report on three adults with chickenpox pneumonia, seen from December 1989 to May 1990, who required ventilatory support and in whom severe life threatening laryngeal oedema developed on extubation.

\section{Case reports}

Case 1-A 33 year old male smoker was admitted five days after the onset of symptoms of chickenpox and two days after chickenpox pneumonia had been diagnosed. He had extensive skin lesions but no mucosal lesions. Two days later he required ventilation and a high volume, low pressure, size $9 \cdot 0$ orotracheal tube (Portex) was inserted uneventfully. On the 17 th day of ventilation his tube became obstructed. No new skin lesions had appeared for 10 days, but a chest radiograph still showed considerable bilateral shadowing. At reintubation visualisation of his larynx showed massive laryngeal oedema; intubation was prolonged owing to anatomical distortion, and he had a cardiac arrest. He failed to regain consciousness and died on the 35th day of ventilation of a pulmonary embolism.
Case 2-A 43 year old male smoker was admitted for ventilation for chickenpox pneumonia four days after the onset of symptoms. He had widespread skin lesions but no mucosal lesions. Intubation with a size $9 \cdot 0$, high volume, low pressure orotracheal tube (Portex) was uncomplicated. On the 14th day no new skin lesions had appeared for seven days and the shadowing in radiographs of the chest had started to clear. He had been breathing spontaneously for 24 hours and was extubated. Four hours later he had increasing stridor and required reintubation. Laryngeal visualisation showed oedematous folds from the laryngeal wall obscuring the whole supraglottic and glottic region. Intubation was prolonged, and he had a hypoxic cardiac arrest, from which he was resuscitated without neurological deficit. On the 18th day tracheostomy was performed, and the tube was removed on the 30th day. On the 31 st day nasolaryngoscopy showed granulomas on the vocal cords but no oedema. The granulomas subsequently resolved.

Case 3-A 73 year old woman with chickenpox pneumonia was admitted two days after developing symptoms with extensive skin lesions but no mucosal lesions. Three days later she required ventilation; intubation with a size $8 \cdot 0$, high volume, low pressure orotracheal tube (Portex) was uncomplicated, and at laryngoscopy the larynx was normal. By the 20th day she fulfilled our usual criteria for extubation, but our 